\title{
VIOLÊNCIAS E TENTATIVAS DE SUICÍDIO EM NARRATIVAS DE MULHERES JOVENS
}

\author{
ACTS OF VIOLENCE AND SUICIDE ATTEMPTS IN NARRATIVES OF YOUNG WOMEN \\ VIOLENCIAS E INTENTOS DE SUICIDIO EN NARRATIVAS DE MUJERES JÓVENES
}

Luana Rodrigues de Freitas Alves Amarante
Luciana Kind

\begin{abstract}
RESUMO
Realizamos uma pesquisa narrativa a fim de compreender a experiência de mulheres jovens que tentaram suicídio. Foram entrevistadas, no período de outubro de 2019 a março de 2020,12 mulheres que atentaram contra suas vidas pelo menos uma vez e estiveram internadas no Hospital Espírita André Luiz, localizado em Belo Horizonte, Minas Gerais. A idade das participantes variou de 20 a 29 anos. A análise das entrevistas guiou-se pelo princípio do tratamento singular de cada história e destaque a episódios transversais a todas elas. Os resultados são apresentados em eixos transversais: abuso sexual, violência nas relaçôes afetivas e violências vivenciadas nas relaçôes familiares. As narrativas apontaram que existe uma relação significativa entre mulheres em situação de violência e a tentativa de suicídio. Porém não se esgotaram as possibilidades de compreensão do fenômeno, porque estamos diante de uma problemática multifacetada.
\end{abstract}

Palavras-chave: Narrativas. Narrativas de mulheres. Tentativa de suicídio. Violência contra mulheres.

\begin{abstract}
We conducted a narrative research to understand the experienced world of young women who attempted suicide. In the period from October 2019 to March 2020, interviews were conducted with twelve women who attempted suicide at least once and were admitted to the André Luiz Spiritist Hospital in Belo Horizonte, Minas Gerais. The age of the participants ranged from 20 to 29 years old. The analysis of the interviews was guided by the principle of the singular treatment of each story, highlighting episodes that cut across all of them. It presented results in transversal axes: sexual abuse, violence in affective relationships, and violence experienced in family relationships. The
\end{abstract}

\footnotetext{
${ }^{1}$ Texto recebido em 10 de agosto de 2018 e aprovado para publicação em 2 de abril de 2019.

Apoio: Fundação de Amparo à Pesquisa do Estado de Minas Gerais (Fapemig).

*Mestra em Psicologia pela Pontifícia Universidade Católica de Minas Gerais (PUC Minas). Endereço: Rua Moassy, 173 - Novo Eldorado, Contagem-MG, Brasil. CEP: 32341-170. E-mail: luanarodrigues.psi@gmail.com

"Pós-doutora em Psicologia Social pela Universidade Federal de Minas Gerais (UFMG), doutora em Saúde Coletiva (IMS/UERJ), docente no Programa de Pós-Graduação em Psicologia da PUC Minas. Endereço: Avenida Itaú, 525 - Jardim São José, Belo Horizonte-MG, Brasil. CEP: 30820-012. E-mail: lukind@gmail.com
} 
narratives pointed out that there is a significant relationship between women in situations of violence and suicide attempt. However, the possibilities of understanding the phenomenon have not been exhausted, since we are facing multilayered problems.

Keywords: Narratives. Women's narratives. Suicide attempt. Violence against women.

\section{RESUMEN}

Hemos realizado una investigación narrativa con el fin de comprender las experiencias de jóvenes mujeres que intentaron suicidarse. En el período de octubre de 2019 a marzo de 2020, se entrevistaron a doce mujeres que atentaron contra su vida al menos una vez y fueron ingresadas en el Hospital Espírita André Luiz, ubicado en Belo Horizonte, Minas Gerais. La edad de las participantes osciló entre 20 y 29 años. El análisis de las entrevistas estuvo orientado por el principio del tratamiento singular de cada narrativa, con énfasis en episodios transversales a todas ellas. Los resultados se presentan en ejes transversales: abuso sexual, violencia en las relaciones afectivas y violencia vivida en las relaciones familiares. Las narrativas señalaron que existe una significativa relación entre mujeres en situación de violencia e intentos de suicidio. Sin embargo, las posibilidades de comprender el fenómeno no se han agotado ya que estamos ante problemas complejos.

Palabras clave: Narrativas. Narrativas de mujeres. Intento de suicidio. Violencia contra la mujer.

\section{INTRODUÇÃO}

0 médico inglês Thomas Browne foi quem definiu, no ano de 1643, o termo "suicídio". Em seu livro, apresenta duas formas de suicídio, uma com conotação "heroica" e a outra de ordem "patológica". Desde então, a temática se tornou um fenômeno de interesse para a psiquiatria (Bertolote, 2012).

Coelho (1997, p. 49) relata que somente

A partir da segunda metade do século XVIII, as punições em relação ao suicida e seus familiares começaram a ser suavizadas; não tanto pela compreensão em relação ao suicídio, mas devido ao fato de o indivíduo isolado perder a importância coletiva que tinha, tanto na antiguidade quanto na idade média (p. 49).

No entanto o suicídio passou a ser cada vez mais considerado como um fenômeno patológico. Apenas no fim do século XIX, o ato foi considerado um fenômeno social (Bertolote, 2012). A consolidação do suicídio pela perspectiva 
da saúde pública se deu entre o fim do século XX e início do século XXI, tendo como ênfase a prevenção de tais comportamentos.

O comportamento suicida tem multideterminaçôes e resulta de diversos fatores de risco (Marín-León, \& Barros, 2003; Meneghel, Moura, Hesler, \& Gutierrez, 2015). Para aprofundar acerca de tais fatores, serão utilizadas as considerações de Bertolote (2012) sobre os fatores predisponentes e fatores precipitantes. Destacamos que essa é uma leitura biomédica sobre o suicídio, bastante difundida no cenário brasileiro. Os fatores predisponentes, também chamados de distais, correspondem ao biológico, e alguns traços de personalidade apresentam-se muito antes do ato suicida. Já os fatores precipitantes, ou proximais, seriam os acontecimentos próximos ao fato. Por exemplo, perdas significativas, situações de humilhação e violência (Bertolote, 2012).

Numa perspectiva sociológica clássica, Durkheim (2000) argumenta que o suicídio não pode ser considerado como tendo uma causa única, afinal diversos acontecimentos podem servir como pretexto. Nas palavras do autor, em cada cultura, existe "uma forma coletiva, de energia determinada, que leva os homens a se matar" (Durkheim, 2000, p. 384). Ou seja, grupos sociais distintos têm distintas inclinações coletivas e que resultam em predisposições individuais para a ideação suicida.

O suicídio representa o ápice de um sofrimento para o ser humano e, diante dessa realidade, vale considerar questões como falta de sentido para existir, medos, conflitos existenciais e até mesmo ajustamentos criativos disfuncionais (Fukumitsu, \& Scavacini, 2013; Fukumitsu, Provedel, Kovács, \& Loureiro, 2015). Fukumitsu e Scavacini (2013), ao falarem sobre suicídio, retomam uma frase-chave da Psicologia da Gestalt, em que diz que "o todo é diferente da soma das partes", e, diante dela, afirmam que "a pessoa que pensa no suicídio deseja eliminar o sofrimento, parte da existência, mas confunde a necessidade de aniquilar seu sofrimento com autoaniquilar-se, matando o todo" (p. 199).

Alguns autores que focalizam essa dimensão do sofrimento pessoal que conduz ao suicídio pressupõem como forma de prevenção o acolhimento e a mobilização que não passe apenas pela expectativa de melhora individual, mas também da ação coletiva promotora de mudanças nos laços daquele, daquela que sofre (Fukumitsu et al., 2015). A mobilização de quem convive ou compõe a rede de cuidados da pessoa que tenta suicídio indica que se fique alerta aos sinais de mudanças repentinas, o que pode auxiliar no surgimento de ações preventivas.

Entre os marcos legais, destaca-se a Lei 13.819, de 26 de abril de 2019, referente à Política Nacional de Prevenção da Automutilação e do Suicídio. No documento, encontram-se questôes como as notificações e o rigor de sigilo das 
informações, porque, dessa forma, seria possível ter mais êxito nos dados, nas ações preventivas e nos tratamentos.

Maciel (2018) apontou uma crescente no número de tentativas de suicídio, em especial no público feminino, responsável por $70 \%$ dos casos, e a faixa etária que mais se contempla está entre 15 e 29 anos. Considerando que as mulheres são as que mais atentam contra a própria vida, este trabalho se direcionou para este público em específico.

A pesquisa de Marín-León e Barros (2003) assinalou que as mulheres utilizam como meio de tentativa a ingestão de medicamentos, envenenamento, arma de fogo e enforcamento. Minayo e Cavalcante (2013) declaram que o suicídio é multifatorial, ou seja, existem diversas razōes para que uma pessoa queira tirar a própria vida. No entanto, estudos envolvendo mulheres apontaram que alguns fatores que estão muito presentes são conflitos conjugais, conflitos familiares, lutos e comorbidades (Correia et al., 2014; Macedo, Rosa, \& Silva, 2011; Meneghel, Hesler, Ceccon, Trindade, \& Pereira, 2013; Minayo \& Cavalcante, 2013; Pinto, Alves, \& Maia, 2015; Santos, Lovisi, Legasy, \& Abelha, 2009; Tavares et al., 2012). Diante dessa realidade, o objetivo desta pesquisa foi compreender histórias de vida de mulheres jovens que passaram pela experiência de tentativa de suicídio. Entendemos que esta pesquisa se soma às encontradas para o aprofundamento da compreensão da experiência de mulheres sobre o suicídio.

\section{METODOLOGIA}

Trata-se de uma pesquisa de cunho qualitativo, com foco em compreender, da perspectiva de quem narra, os sentidos e significados atribuídos à experiência vivida (Minayo, 2007). Foi utilizada como método de produção de material empírico a pesquisa narrativa. Pelas narrativas, é possível abordar, de modo mais amplo, o mundo experienciado da pessoa que conta sua história (Flick, 2009). A entrevista narrativa tem como base uma "pergunta gerativa de narrativa" e é de natureza não estruturada. Por ela, é possível aprofundar em características específicas sobre um determinado contexto importante de sua vida e do contexto social em que está inserida. Ela tem como finalidade encorajar a entrevistada a contar sua história (Flick, 2009; Jovchelovitch, \& Bauer, 2007).

Jovchelovitch e Bauer (2007) apresentam as características da entrevista narrativa. De acordo com esses autores, a entrevista narrativa é composta por quatro fases: 
1) apresentação da pesquisa e da pergunta principal;

2) narração principal, com o mínimo de interrupções por parte da pesquisadora;

3) questionamento e aprofundamento;

4) comentários adicionais.

Nesta pesquisa, a questão gerativa foi: "Conte-me sobre sua história de vida e experiência com a tentativa de suicídio. Você pode levar o tempo que for preciso e pode dar detalhes de tudo o que for importante para você”. Como se vê nessa questão e no objetivo geral da pesquisa, não havia um foco inicial na relação entre tentativas de suicídio e violência contra mulheres. Contudo, na escuta atenta das narrativas, essa associação se sobressaiu, impondo-se a discussão específica sobre violências como relato central da pesquisa.

Foram realizadas entrevistas com mulheres que passaram por, pelo menos, uma tentativa de suicídio, mas que estavam com quadro clínico estável e que receberam acompanhamento clínico em serviço de atenção do Hospital Espírita André Luiz (HEAL), instituição beneficente de assistência à saúde mental de Belo Horizonte. O contato com a equipe multiprofissional do hospital auxiliou para compreensão das condições estáveis de saúde para participação de uma pesquisa. Caso fosse verificada ideação suicida na fala das jovens durante a entrevista, elas seriam encaminhadas para serviços de apoio no próprio hospital. Não foi necessário realizar nenhum encaminhamento.

Reconhecemos que o tema e os critérios de inclusão de participantes mostram uns cenários de pesquisa de "tópicos sensíveis" (Hydén, 2013). A escolha por não realizar a entrevista em período de internação se deu para evitar conflitos entre o objetivo do tratamento terapêutico e o da pesquisa. As entrevistas foram realizadas com muita cautela e respeitando os limites das mulheres ao narrarem suas histórias, por se tratar de uma experiência que envolve sofrimento. A pesquisadora tem experiência no atendimento com esse público e desenvolveu a pesquisa em diálogo com a equipe do serviço de saúde, assegurando-se a possibilidade de acioná-la sempre que necessário.

A pesquisadora atuou no setor de psicologia da internação do Hospital Espírita André Luiz, instituição que acolheu e acompanhou a execução da pesquisa. Em sua prática clínica, continua realizando atendimentos psicoterápicos de jovens e mulheres com ideações suicidas.

Os procedimentos descritos a seguir foram submetidos à apreciação do Comitê de Ética em Pesquisa da PUC Minas, obtendo-se à aprovação do projeto de pesquisa (Parecer no 3.564.197). Foram realizadas 12 entrevistas no período 
de outubro de 2019 a março de 2020, majoritariamente no consultório da pesquisadora e, em alguns casos, na casa das entrevistadas. Os dias, horários bem como o local foram acordados com cada participante, considerando o que ficaria mais adequado a suas dinâmicas de vida.

Os critérios de inclusão das participantes foram ter ficado internadas após tentativa de suicídio no hospital parceiro e terem recebido alta há, pelo menos, seis meses. Tinham idade igual ou superior a 18 anos e, no máximo, 29 anos, considerando somente a participação de jovens, uma vez que o último boletim do Ministério da Saúde apontou para um crescente aumento de tentativas e suicídios nessa faixa etária e serem consideradas juridicamente capazes (Maciel, 2017).

Foram realizadas duas reuniōes com a equipe do hospital para alinhamentos necessários em relação aos aspectos. Para auxiliar na comunicação, foi criado um grupo de WhatsApp e um arquivo no Google Drive, alimentado tanto pela equipe do hospital quanto pela pesquisadora. A equipe que deu suporte ao desenvolvimento desta pesquisa estava composta por uma psicóloga, coordenadora da equipe de Psicologia, uma enfermeira, coordenadora da equipe de Enfermagem, um médico psiquiatra assistente e um assistente do Setor de Psicologia. Esse grupo de profissionais realizava a triagem das pacientes e alimentavam a planilha no Google Drive apenas com informações básicas e relevantes para a pesquisa, como nome, telefone para contato, data de nascimento e data da alta.

Após fazer contato com as mulheres indicadas, a pesquisadora adicionava uma observação, dizendo se as havia entrevistado ou não. Vale considerar que a pesquisadora não tinha acesso a nenhum documento interno do hospital nem histórico das mulheres indicadas para a entrevista. A planilha foi alimentada com novos contatos por cinco vezes, totalizando 60 indicações. Como o número de retornos negativos foi considerável, decidiu-se por findar as indicaçôes quando se chegou a 12 entrevistadas. Os motivos pelos quais as demais 48 entrevistas não se concretizaram foram diversos. Algumas mulheres se recusaram a participar por acreditarem que ainda não estavam prontas para falar sobre o suicídio, outras por distanciamento físico e, ou, dificuldades com suas rotinas. Outras indicadas, ainda, não deram retorno às tentativas de contato e, em alguns casos, os responsáveis pelos cuidados não permitiram que a jovem se disponibilizasse a participar.

As mulheres que não retornaram o contato realizado foram respeitadas e não houve insistência, para não gerar desconforto e sentimento de obrigação. O contato foi realizado sempre com a intenção de não se tornar invasivo e de 
maneira a deixar as mulheres livres para participarem apenas se sentissem que "estavam prontas para falar", como algumas entrevistadas marcaram. Falas como "é tranquilo falar sobre isso" ou "quero poder ajudar outras mulheres que passam pela mesma situação que eu" estiveram presentes em alguns retornos positivos.

No quadro 1, são apresentadas as características das participantes. Os nomes fictícios foram escolhidos por elas, exceto quando se aproximaram muito de seus nomes reais e foi preciso realizar alterações por precauções, para que elas não fossem identificadas.

Quadro 1 - Características das mulheres entrevistadas

\begin{tabular}{|c|c|c|c|c|c|c|c|}
\hline $\begin{array}{l}\text { Nome } \\
\text { fictício }\end{array}$ & $\begin{array}{l}\text { Idade } \\
\text { (anos) }\end{array}$ & $\begin{array}{l}\text { Quantas } \\
\text { tentativas }\end{array}$ & Trabalho & Estado civil & Filhos & Escolaridade & Tratamento atual \\
\hline Marina & 23 & $\begin{array}{l}\text { Perdeu as } \\
\text { contas }\end{array}$ & Não & Solteira & Não & $\begin{array}{l}\text { Superior em } \\
\text { curso }\end{array}$ & Sim \\
\hline Laura & 29 & 4 & Autônoma & Casada & $\operatorname{Sim}(1)$ & $\begin{array}{l}\text { Superior com- } \\
\text { pleto }\end{array}$ & $\begin{array}{l}\text { Interrompido por } \\
\text { causa da gestação }\end{array}$ \\
\hline Camila & 27 & 8 & $\begin{array}{l}\text { Empresa da } \\
\text { família do } \\
\text { marido }\end{array}$ & $\begin{array}{l}\text { Solteira/ } \\
\text { União } \\
\text { estável }\end{array}$ & $\operatorname{Sim}(2)$ & $\begin{array}{l}\text { Ensino Médio } \\
\text { Completo }\end{array}$ & Sim \\
\hline Gabriela & 28 & 1 & Sim & Solteira & Não & $\begin{array}{l}\text { Superior com- } \\
\text { pleto }\end{array}$ & Sim \\
\hline $\begin{array}{l}\text { Dame } \\
\text { Vide }\end{array}$ & 22 & 4 & Não & Solteira & Não & $\begin{array}{l}\text { Superior com- } \\
\text { pleto }\end{array}$ & Sim \\
\hline Flor & 29 & 8 & Não & Solteira & Não & $\begin{array}{l}\text { Superior in- } \\
\text { completo }\end{array}$ & Sim \\
\hline Alice & 26 & 2 & Não & Solteira & Não & $\begin{array}{l}\text { Superior in- } \\
\text { completo }\end{array}$ & Sim \\
\hline Júlia & 24 & $\begin{array}{l}\text { Perdeu as } \\
\text { contas }\end{array}$ & Não & Solteira & Não & $\begin{array}{l}\text { Superior in- } \\
\text { completo }\end{array}$ & Sim \\
\hline Pietra & 20 & 2 & Autônoma & Solteira & Não & $\begin{array}{l}\text { Superior em } \\
\text { curso }\end{array}$ & Sim \\
\hline Juliana & 21 & 8 & Não & Solteira & Não & $\begin{array}{l}\text { Superior em } \\
\text { curso }\end{array}$ & Sim \\
\hline Olívia & 22 & $\begin{array}{l}\text { Perdeu as } \\
\text { contas }\end{array}$ & Não & Solteira & Não & $\begin{array}{l}\text { Superior em } \\
\text { curso }\end{array}$ & Sim \\
\hline Cris & 28 & $\begin{array}{l}\text { machucou-se } \\
\text { umas } 30 \\
\text { vezes }\end{array}$ & Sim & Solteira & Não & $\begin{array}{l}\text { Superior com- } \\
\text { pleto }\end{array}$ & Sim \\
\hline
\end{tabular}

Fonte: elaborado pelas autoras.

A idade das mulheres variou entre 20 e 29 anos. Destas, 10 eram solteiras, 1 era casada e 1 vivia em união estável havia mais ou menos um ano quando da 
realização das entrevistas. Apenas duas mulheres eram mães. Vale ressaltar que, na data da entrevista, uma delas estava em dias finais da gestação da primeira filha, e a outra não tinha a guarda de suas duas filhas, mas queria recorrer judicialmente para poder reverter a situação. Quanto à escolaridade, 1 havia concluído o ensino médio, 4 tinham curso superior completo, sendo que 2 atuavam na área de formação, 1 não estava trabalhando, e a outra, formada em Direito, trabalhava administrando a fazenda do pai. Outras 4 estavam em processo de formação no curso superior, e outras 3 interromperam a graduação por acreditarem que, por ora, não tinham condições psicológicas de concluí-la.

Das 12 participantes, 4 afirmaram que perderam as contas de quantas vezes recorreram à tentativa de suicídio como opção diante de algum conflito; 2 mulheres tentaram 8 vezes; 2 fizeram 4 tentativas; e outras 2 tentaram 2 vezes. Quanto às demais, 1 tentou 7 vezes; e a outra, apenas 1 . O método mais utilizado por 11 delas foi a ingestão de medicamentos psiquiátricos. Uma tentou pular de um viaduto e foi impedida por um taxista que passava no momento, outras 3 tentaram pular das janelas de seus apartamentos e foram impedidas por vizinhos ou familiares. Três mulheres cortaram os pulsos, e todas foram encontradas por familiares e encaminhadas a serviços de pronto atendimento. Duas entrevistadas relataram que, em uma de suas tentativas, fizeram a combinação de processos. Uma combinou medicação, cocaína e bebida alcoólica; e a outra, ingestão de medicação e corte nos pulsos.

O Ministério da Saúde (2006) aponta como um fator protetivo o encorajamento da fala sobre os pensamentos e ideações suicidas, bem como sobre suas experiências de sofrimento. Relata-se que as pessoas tendem a ficar agradecidas e aliviadas, e que isso não representa que a ideação será incutida no sujeito. Tendo em vista todos os cuidados éticos relatados, acreditamos que o desenvolvimento da pesquisa se alinhe com esse fator protetivo e que as participantes vivenciaram a entrevista como uma oportunidade de narrar suas próprias experiências.

A análise das entrevistas se guiou pela proposta de Faúndez, Cancino e Besoain (2017), tecendo-se uma primeira etapa que enfatiza a lógica singular e uma segunda que segue uma lógica transversal. A seleção de fragmentos narrativos, terceira etapa do processo de análise, pressupõe a combinação das duas etapas e orienta a apresentação dos resultados. Neles, mantém-se a voz singular das entrevistadas, respeitando-se a composição narrativa que lhe é peculiar, mas o pressuposto é de que cada fragmento em destaque ressoa temas e histórias transversais ao conjunto das entrevistas. Concordamos com Faúndez, Cancino e Besoain (2017) quando argumentam que as narrativas se estruturam como modo de recontar uma história vivida como singular, todavia carregam em si 
marcas de realidades sociais mais amplas. Com esse argumento em perspectiva, o dispositivo analítico articulou uma lógica singular, a fim de fazer emergir das narrações das participantes aspectos de suas experiências e subjetividades. A lógica transversal se consistiu na aproximação de experiências, localizando pontos de convergência entre as 12 entrevistas. Os resultados, recortes feitos na terceira etapa, são apresentados como articulação simultânea entre histórias singulares que ecoam e se articulam a outras histórias.

Como modo de operacionalizar esse percurso analítico, um primeiro momento constituiu-se da escuta e leitura simultâneas das histórias de vida das mulheres que passaram pela experiência da tentativa de suicídio, com registro de episódios marcantes em cada uma delas. No segundo momento, ainda em contato com arquivo de áudio e transcrição das entrevistas, foram identificados episódios que ganharam destaque e se entrelaçavam a outras histórias. Na terceira etapa, os pontos de convergência derivados dessa lógica transversal configuraram-se como eixos temáticos ordenadores das experiências, que se expressaram em fragmentos narrativos relatados por uma das doze entrevistadas, mas que condensassem experiências compartilhadas por mais de uma delas. Os resultados foram organizados nos seguintes eixos analíticos, que trazem elementos transversais às entrevistas: abuso sexual, violência nas relações afetivas e violências vivenciadas nas relações familiares. Por meio desses eixos, são apresentados os resultados e discussōes deste estudo.

\section{RESULTADOS E DISCUSSÕES}

Os fragmentos narrativos trazidos para o artigo foram apresentados com base em uma estrutura mínima de início, meio e fim, respeitando-se a ordem de eventos que compõem cada história. No que tange ao abuso sexual, foram considerados os casos em que as participantes foram coagidas a terem relaçóes sexuais indesejadas. Tanto no eixo que aborda a violência nas relações afetivas quanto nas relações familiares, foram consideradas situaçôes em que houve agressões físicas e psicológicas.

\subsection{ABUSO SEXUAL}

De acordo com o boletim epidemiológico divulgado pelo Ministério da Saúde (2018),

A violência tem consequências profundas para a saúde física e mental nas pessoas que a vivenciam, tendo impacto no desenvolvimento psicossocial das crianças e adolescentes, 
no bem-estar das famílias e das comunidades, constituindo-se em desafios para os gestores e profissionais da saúde (p. 10).

Aqui vamos apresentar algumas narrativas de jovens que foram abusadas sexualmente no período da infância e adolescência, sendo que todas elas passaram por mais de uma situação de violência sexual. Marina foi abusada sexualmente três vezes, sendo que as duas primeiras foram por dois vizinhos, e a terceira, pelo próprio irmão mais velho.

Eu fui abusada de quando eu era pequena [. . . Primeiro foi o vizinho aqui de casa, começou tudo com 6 anos de idade. Minha mãe me deixava por necessidade de ter que resolver as coisas, né? [. . . ] fala que criança esquece. Mas criança nunca esquece. Ele passou a mão na minha parte íntima (breve pausa) e ficava fingindo que lá, eu queria andar de bicicleta, mas eu não sabia andar de bicicleta e lá tinha uma bicicleta de exercício e ficava assim "vem cá, vem cá andar de bicicleta”, e depois que ele passou a mão na minha parte íntima eu fiquei tão assim "meu Deus, que isso!" (Marina).

Assim como Marina, Dame Vide foi abusada por três vezes e por pessoas diferentes. Faz questão de frisar isso em sua fala:

Eu já fui estuprada três vezes, por três pessoas diferentes, em três épocas diferentes da minha vida. Então assim, (gagueja) foi [...] Foi difícil sabe [...] A primeira vez, foi um primo meu, que tem problema mental. [...] Eu sempre escondi isso, sabe, essa questão do estupro por medo mesmo, sabe. Os outros casos foi um professor particular, e aí o outro caso foi um amigo mesmo (Dame Vide).

Alice contextualiza que, após a separação dos pais, a mãe iniciou uma nova relação e, em pouco tempo, foram morar na casa do novo companheiro. E nesse novo contexto, ela sentia que a mãe estava abandonando os filhos da primeira relação e, com isso, ficou muito próxima do filho do padrasto. Relata que acabou criando

Uma confiança muito grande nele, que ele acabou usando pra [...] Pra poder se [...] Pra poder abusar de mim assim [...] Que, muitas vezes, eu não sabia o que tava acontecendo, mas tava acontecendo [...] Eu me lembro [...] A primeira vez que eu fiz sexo oral nele, e ele pediu, e eu falei "Mas o que que é isso?". Eu nem sabia o que que era assim, sabe, era muito estranho (Alice).

Alice também passou por experiências de violência sexual com o avô paterno. Relata que ele "Ficava oferecendo dinheiro pra andar pra ele [...] sem roupa em casa, ficava se masturbando no sofá [...] E eu não sabia o que era né”. Olívia também se sentiu violada e invadida após reencontrar um amigo de infância. 
Era um amigo da família, e eu brincava muito com ele, né, até os meus 8 anos de idade. Depois disso, ele mudou de casa, aí eu não [. . . en encontrei com ele mais, eu também mudei [...] Aí a gente começou a conversar e tudo. Ele pediu meu telefone, pediu meus contatos, pediu para ir na minha casa [...] E eu achei estranho né, a velocidade que as coisas foram acontecendo, porque, num dia, ele me pediu meu telefone e, no outro dia, ele tava na minha casa me esperando chegar da escola. [...] E aí a gente começou a sair algumas vezes, e tudo, lá perto da minha casa mesmo. A gente foi na sorveteria, nesses lugares assim, porque até então também eu não saía sozinha. [. . .] Então eu comecei a interessar por ele, e eu tocava violão [. . .] então eu resolvi compor uma música para ele. Eu nunca tinha composto uma música nem nada, mas foi ali naquele momento de sentimento e tudo mais, aí eu compus uma música. Aí eu chamei ele para poder escutar essa música, mas ele me enrolou durante sete meses pra aparecer (risos), e aí eu fiquei naquela expectativa, fui me frustrando mais [. . .]. Aí esse menino reapareceu e me pediu para ir na casa dele pra tocar a música pra ele. E aí foi quando aconteceu o meu primeiro abuso sexual. Ele me forçou a ter relações com ele. Eu não sabia que ele trabalhava pra polícia, ele era da polícia, e, quando eu fui na casa dele, toquei a música e tudo mais, ele foi e falou que queria ficar comigo, que gostava muito de mim, mas que ele tinha voltado com a ex-namorada dele por [. . . pressão da família, por pressão das pessoas, e que ele não conseguia sair disso, mas que ele queria ficar comigo. E aí ele ficou insistindo naquilo e naquilo, e aí, quando eu falei com ele que não, aí ele pegou a arma, foi quando eu descobri que ele era policial, (bem baixinho) ele apontou a arma na minha cabeça, e foi um momento de trauma na minha vida, porque ali encerrou tudo que eu acreditava. Que até então eu não tinha tido nenhuma relação sexual, eu pensava em casamento, pensava em casar virgem, pensava nisso, então ali ele destruiu todos os meus conceitos, ele tirou tudo de mim naquele momento (Olívia).

Esse é o relato do primeiro abuso sexual que Olívia sofreu. Ela teve um segundo abuso, perpetrado pelo professor de Educação Física da escola. Neste, o vigia da escola a socorreu e deram queixa do professor: "E aí, quando eu sofri esse segundo abuso, eu falei 'que vergonha, meu corpo foi violado duas vezes, (voz chorosa) tudo que eu acredito tá sendo jogado fora, e eu não consigo fazer nada, eu não consigo reagir diante disso'”. O terceiro e último abuso foi o esposo da tia: "Pra mim foi a pior coisa do mundo, porque ele me chamou pra dar aula de violão pra ele [.. . ] quando eu consegui pegar no violão de novo, ele destruiu aquilo de novo. Então foi um momento muito difícil pra mim”. A família da jovem teve conhecimento dos dois últimos abusos, sendo que, no primeiro, o professor foi denunciado e, no segundo, a família escolheu não prestar queixa por se tratar de uma pessoa da família.

De forma geral, todas as mulheres disseram que ainda é difícil falar sobre a violência sofrida e que o fato de serem invadidas afetou o emocional e, consequentemente, influenciou na decisão de dar fim à própria vida.

Durante a fase central da narração de Alice, foi apontado que ainda se sente presa à experiência de abuso sexual vivenciada e que, por não conseguir 
se desprender e, em determinados momentos, as lembranças aparecerem 'mais fortes', recorria ao suicídio como forma de acabar com seu sofrimento. Ao narrar uma de suas tentativas de autoextermínio, Olívia disse que só pensava que queria morrer e que "queria dar um fim naquele sofrimento". De acordo com ela, os abusos tiraram a possibilidade de uma construção de vida conforme o que havia sonhado e planejado para seu futuro.

\subsection{VIOLÊNCIA NAS RELAÇÕES AFETIVAS}

Nesta seção, serão apresentadas narrativas que contemplam violência psicológica e física em que os agressores foram os parceiros íntimos.

Com 14 anos, eu comecei a namorar um menino da escola. Namorei com ele por dois anos e meio, fiquei noiva dele seis meses [...] É [...] Muito nova, mas, enfim, as circunstâncias eram, eram [...] Fazia sentido, sabe? A gente ficar noivo e tal. É [...] Mas aí ele foi um crápula comigo. Eu terminei com ele, ele não aceitou [...] E aí, enfim, a gente era um casal né, então fotos íntimas e tal, e aí basicamente quando eu terminei, ele não aceitou ele né [...] Jogou tudo na rede, na escola e tal [...] Então ali começou o meu, meu [...] Meus primeiros pensamentos de me matar. E ali começou também a minha depressão, sabe? Foi uma coisa assim, horrível. Nossa, foi horrível! (Dame Vide)

Um namoro $[\ldots]$ que me colocava totalmente pra baixo o tempo inteiro. É $[\ldots]$ eu briguei com Deus e o mundo pra ficar com essa pessoa, [. . . ] me cobrava demais a questão de corpo [. . .] eu cheguei a morar um tempo com ele, porque meu pai não aceitava, meu pai sabia da história toda dele, e meu pai não aceitava, meu pai foi e falou comigo "Se você quiser namorar com ele, é do portão pra fora. Aqui dentro da minha casa, eu não aceito ele". Aí resolvemos ir morar juntos, com toda essa situação. Só que foi só piorando, agravando a minha doença que eu já tinha, porque aí ele fazia tudo isso. [. . .] se eu tivesse indo com X calcinha é porque eu tava pensando em fazer algo errado na faculdade. Então foi um negócio que foi mexendo demais com a minha cabeça. E a questão das cobranças, e a questão da traição. Eu descobri as traiçōes, não conseguia, brigava, esbravejava, aquela coisa toda, mas não conseguia pôr um fim no relacionamento. Eu dependia emocionalmente dele (Laura).

Só que ele era uma pessoa super obsessiva. [. . . ] como eu morava em outra cidade, e ele tinha que trabalhar, e tinha que estudar, e tinha que fazer várias outras coisas, e eu também tinha que estudar, ele ficava superciumento, e aí ele me deu um celular e ficava me ligando 24 horas por dia. Eu tinha que deixar meu celular sempre carregado, porque ele me ligava literalmente o tempo todo. E não era tipo ele me ligava e desligava, e ligava e desligava, ligava e desligava. Ele ligava e deixava ligado a ligação enquanto eu vivia a minha vida pra saber o que que eu tava fazendo. [. . .] Era como se eu fosse o bichinho de estimação dele, eu sempre tava lá pra ele. É, ele conseguiu manipular a minha mente pra acreditar em coisas que eu não consigo nem imaginar que eu 
acreditei. Eu fico perplexa com o como ele conseguiu me manipular com palavras tão simples e coisas tão sensíveis (Pietra).

Pietra vivenciou mais dois namoros abusivos e relata que, em todos, sofreu com agressões físicas e que não sabia o que fazer para sair do relacionamento. Apesar de sentir-se oprimida, "não pensava na pessoa como um agressor", o que contribuiu para permanecer mais tempo no enlace afetivo. Em um dos namoros, conta que sua vida "virou um inferno" e que recorrer à tentativa de suicídio era uma forma de se livrar dessas violências.

Eu lembro que, até os seis meses de namoro, eu já tava me perguntando se eu era louca, ou [...] se eu não tinha deixado de ser eu mesma, ou se, ao mesmo tempo, eu tinha feito isso tudo e eu tava perdendo a minha vida do lado daquela pessoa. Seis meses de namoro. Eu namorei quase três anos com esse cara [. . . ] foi horrível pra mim. Era tipo, eu não queria transar, eu tinha que transar, era eu não queria ir num lugar e eu tinha que ir, eu queria ir num lugar e eu não podia, eu queria conversar com os meus amigos e eu não podia, eu queria fazer alguma coisa, eu não podia. Mas se eu não queria, provavelmente eu teria que fazer. Era isso que eu tinha durante quase três anos da minha vida (Pietra).

A violência psicológica é considerada a que mais traz perdas para a autoestima e subjetividade das mulheres (Guimarães et al., 2018). Normalmente atos mais agressivos são facilmente identificados como violências. Porém comportamentos como perseguição e manipulação são menos reconhecidos, o que pode contribuir para que muitas mulheres não percebam que estão dentro de uma relação abusiva (Souza, Pascoaleto, \& Mendonça, 2018).

Segundo Souza, Pascoaleto e Mendonça (2018), os atos agressivos começam com insultos, humilhações e intimidações. Falas depreciativas e de inferiorização da mulher podem ser seguidos, em casos extremos, de agressões físicas. Algumas jovens narraram ameaças de agressão ou o ato propriamente dito e apresentaram que o sentimento de incapacidade para romper com as violências fazia com que tentassem pôr um fim na situação e, consequentemente, na vida.

Roberto veio de um jeito que ninguém tinha vindo, assim, de querer cuidar, de querer resolver tudo, de querer resolver minha vida inteira [. . .] Só que ele era muito controlador, sabe, ele queria controlar tudo. Tanto que eu fiquei quatro meses sem ver os meus amigos logo depois de começar a namorar com ele. Que, se eu saía, ele queria saber onde que eu tava, com quem que eu tava, que horas que eu iria voltar, que roupa eu tava usando, que batom eu tava usando e tudo. E ele não fazia questão também de estar ali, sabe, de ir comigo nas coisas, de viver as coisas comigo [. . .] Depois que eu terminei com ele, eu acabei conhecendo o Fábio [. . . ] era realmente muito carinhoso comigo. No começo, saiu muito comigo, com os meus amigos, fez tudo certinho até o dia que ele bebeu. $\mathrm{O}$ dia que ele bebeu, ele tentou me agredir [...] Ficou agressivo 
comigo, ficou falando que eu era muito corajosa de estar perto dele, que, se ele me desse um soco, que ele me desmontava (Alice).

Muito difícil! Era bem difícil mesmo, a gente (se referindo ao ex-namorado) brigava muito [. . .] da mãe dele perguntar se ele já tinha me batido. Ah, às vezes, ele me empurrou no chão, coisas assim do tipo, e aí foi até a gente resolver terminar. Aí quando a gente começou a namorar, eu não podia conversar com ninguém, meu telefone tinha, eu tinha que [... .] eu tinha que almoçar com o telefone ligado, porque ele tinha que ouvir com quem que eu tava almoçando. Foi, foi bem difícil (Cris).

Na minha festa de 15 anos, ele chegou no meu pai e falou "Eu quero, eu tô namorando sua filha”. A partir daí, eu tava namorando, e eu não pude falar nada, e ele era muito abusivo. Eu não podia sair com ninguém. Ele ligava para os amigos, ele xingava meus amigos, ameaçava, é [...] Eu podia sair só com ele, todos, tudo assim, muitas brigas, muitas brigas, horríveis, horríveis assim [. . . ele virava pra mim e falava assim "Sua mãe é horrorosa! Sua mãe é a mulher mais feia que eu já vi. Não sei como seu pai casou com ela. Todo mundo fala que sua mãe é feia, você puxou ela”. Sabe, era umas coisas assim, e a gente terminou porque ele me bateu, ele me agrediu. Aí ele me agrediu, e eu dei, eu fiz o boletim de ocorrência. Na época, não existia nada disso de Maria da Penha, de abuso com as mulheres. Então não foi pra frente nada, e ele ainda queria continuar o namoro, e não continuamos. Eu falei "Não, chega!", eu tava numa situação com ele de que eu tava com ele porque eu não tinha saída, aí, no depois que aconteceu isso, que ele me bateu, que eu falei "acabou", eu falei "cara, se não acontecesse isso, eu não tinha terminado com ele" (Flor).

Lawrenz et al. (2018) apontaram que, na maioria dos casos, a violência física é acompanhada de abusos psicológicos, como é possível notar no relato de Flor. Apesar de o namorado de Alice não ter chegado às vias de fato, ele usou da ameaça para intimidá-la.

\subsection{VIOLÊNCIAS VIVENCIADAS NAS RELAÇÕES FAMILIARES}

Algumas jovens vivenciaram agressões físicas e psicológicas por parte de seus familiares, especialmente de seus pais e mães. Em alguns casos, as agressões foram direcionadas a elas e, em outros, elas presenciaram cenas de violência doméstica. Também há relatos de sobrecarga, por desempenhar muitos papéis ou por assumirem precocemente os cuidados da casa.

Dos meus 6 aos meus 12 anos, eu apanhava todos os dias. E eu apanhava por causa do meu irmão, porque eu era uma pessoa muito quieta, eu sempre fui muito introspectiva. E o meu irmão fazia muitas coisas assim, artes de criança, sabe? Tipo pintar a cara de cachorro, subir no telhado [...] E aí meu pai entendia aquilo como uma coisa ruim, e batia em mim, porque eu tinha que ter obrigação de olhar meu irmão, e meu irmão não podia fazer essas coisas, me batia porque meu irmão não tirava nota boa na escola, e eu tirava (Olívia). 
A jovem conta que, durante um período de sua infância, ficava na casa da avó, e foi um período que apanhou muito do pai, porque ela dizia que haviam aprontado e era motivo para brigas. Até que, aos 9 anos, a mãe a ensinou a cozinhar, arrumar casa e passou as regras para que ficasse em casa sozinha, cuidando do irmão enquanto eles estavam trabalhando. Relata que, com isso, sua responsabilidade aumentou muito.

A minha mãe e meu pai são casados têm, vão fazer 31 anos de casado agora. E é o caos. A minha mãe sempre foi muito agressiva, muito agressiva comigo, com meu irmão. A gente cresceu assim na base do [. . . ] de apanhar, sabe? E do grito, tudo de uma maneira muito agressiva, sabe, sempre. Qualquer coisinha vira pivô pra uma briga enorme, pra confusão pra grito, pra xingo, pra bater e quebrar as coisas. Então, assim, sempre tive essa infância muito conturbada. [. . .] Ela (mãe) sempre teve muito em casa, mas, ao mesmo tempo, era como se não tivesse, porque ela não fazia a menor questão da gente. Sempre muito fria, muito distante. Então, meu pai sempre muito ausente por conta do trabalho (Dame Vide).

Ao contar sobre a exposição de sua imagem feita após o término de um relacionamento, relata como foi o recebimento da notícia para sua mãe:

Eu nunca vou esquecer aquele dia, 3 de setembro de 2013. Ali [...] Ali a minha vida acabou. Porque, foi horrível assim, pra mim, pra minha família né [. . .] A coordenadora chamou a minha mãe na escola, a minha mãe chegou lá e me deu um tapa na cara, me chamando de vagabunda na frente da coordenadora. Então, assim, eu passei muito, muita vergonha, sabe? E ela começou falar né, que eu era uma vergonha, que ela nunca mais ia ter orgulho de mim, que eu era sempre, que eu ia sempre ser uma vergonha pra ela, que ela tinha muito desgosto de mim (Dame Vide).

Minha infância foi bem [...] não foi uma coisa legal. (breve pausa) Igual, meu pai e minha mãe se separaram. Porque até então eu tinha achado que, porque meu pai bateu na minha mãe, batia nela, mas eu pensava que era aquele bater normal. E aí quando a minha psicóloga começou a perguntar meus pais sobre o que aconteceu, minha mãe, finalmente, depois de muitos anos, me contou que, na verdade, meu pai tinha espancado ela. Espancado ela feio, deixado ela no chão de um jeito que ela não conseguia nem mexer. E que ela teve que chamar meu vô e minha vó pra levar ela no hospital (Júlia).

Ao contar sobre um fim de semana na casa do pai, quando tinha 11 anos, Júlia narra a agressão contra sua madrasta

Pegou ela assim, pelo pescoço, e levantou ela assim na parede (demonstrando como o pai fez), e eu assim arregalei os olhos desse tamanho (faz cara de assustada). Fiquei assim "Meu Deeeeeus!". Ficou eu e ela tentando empurrar meu pai, empurrar meu pai até que a gente conseguiu empurrar ele e jogar ele no sofá. Aí a gente entrou no quarto e fechou a porta. Ficou lá dentro. Ficou eu e ela chorando a noite toda. Ela chorando 
pelo cara que ela casou, e eu chorando pelo cara que eu achei que era meu pai, mas que não era (Júlia).

Júlia vivenciou agressões do pai para com a mãe, do pai em relação à madrasta e presenciou o padrasto batendo na mãe. Quando ela relata a situação com a madrasta, fica evidente que, para ela, foi processual o entendimento de que seu pai era violento. Dame Vide também relata ter presenciado violência entre os genitores. Em determinado momento da entrevista, relata que já tiraram sangue no outro. O ponto que distancia as histórias das duas é que a primeira nunca teve episódios direcionados a ela. Já a segunda também sofria com as agressôes por parte da mãe.

A minha família já é totalmente diferente de mim. Eles não me passam amor, eles não me dão atenção, é [...] Me machucou muito quando a minha mãe pegou a guarda das minhas filhas, porque eu não esperava isso dela [...] Desde os 16 anos que [...] Eu comecei a namorar com o pai das minhas filhas, que eu venho enfrentando a minha família, porque eles não aceitavam meu relacionamento com ele. Então eu venho sendo uma filha desobediente para eles. Aí passamos por tudo, foram oito anos de relacionamento, até que aceitaram meu esposo, aí ele vai e morre. [. . .] Na minha cabeça, eu tinha que dar um pai pras minhas filhas. Elas não podiam ficar sem um pai, sem uma referência masculina. Só que eu não queria que meu pai fosse a referência masculina na vida delas, porque meu pai, ele me agrediu muito quando eu era pequena [...] Ele agredia, às vezes, sem motivo nenhum! Chegava cansado do serviço, era um motivo pra agredir eu e a minha irmã. Aí, até hoje, eu tenho dificuldade de [...] De chegar perto do meu pai [. . .] Eu fui cansando a minha mãe, né, ela foi ficando cansada, porque ela viu que eu não levava a sério o tratamento. Tanto que, hoje em dia, ela nem se preocupa se eu tô bem ou se eu tô mal (Camila).

Ficava muito estressada, porque eu tinha que dar conta de duas crianças, de casa, de tudo, né? E ficava muito em casa, não saía. Aí comecei a ficar mais depressiva nessa época. Mas nunca deixei de ser uma boa mãe, de deixar a casa limpa, de dar as coisas que minhas filhas precisavam. Só deixei de sorrir. Meu esposo até reclamava disso (Camila).

Nos relatos acima, Camila aponta para vivências de dificuldades e agressões em seu núcleo familiar primário e a sensação de sobrecarregada pelos afazeres destinados a ela na relação com o namorado após a união estável. Ela ainda reforça que teve um bom comportamento, uma vez que "nunca deixou de ser uma boa mãe" nem de limpar a casa. Em consonância com Meneghel et al. (2013), é como se as mulheres não pudessem expor seus sentimentos e devessem simplesmente aceitar o papel que lhes foi concedido.

Ele (o pai) gritava, batia na mesa, e o fato de tipo eu era pequena e, às vezes, chorava com medo de escuro. Ele achava que eu tinha que ficar no escuro pra ver que não 
tinha nada. Aí, ele me colocava de castigo no escuro porque não tinha nada. E assim, são poucas as coisas que eu lembro, sabe. Eu não lembro muito. Eu lembro assim de sempre tá chorando e de quando eu tava adolescente, ele falar que, tipo, ah, se eu não quisesse seguir as regras da casa que eu podia ir embora. Às vezes, brigava por causa da roupa que eu tava, brigava e falava que eu podia sair de casa. [. . . ] tanto que eu tenho pavor até hoje só de pensar que eu posso voltar pra casa. Tenho pavor! Pavor mesmo! (Cris)

Pela violência psicológica, física e até mesmo pela sobrecarga vivenciada, todas as participantes foram afetas em alguma instância e apontaram tais experiências como fatores que influenciaram nas decisões de tentativa de suicídio. A internalização de situações violentas pode vir a minar forças psíquicas e realimentar traumas, de forma que tais mulheres revisitem interiormente os sentimentos e sensações, e queiram pôr um fim em tudo (Minayo, \& Cavalcante, 2013).

\section{CONSIDERAÇÕES FINAIS}

As experiências de violência narradas pelas jovens entrevistadas não eram uma associação pressuposta nesta pesquisa, ao contrário do que lemos em outros estudos (Correia et al., 2019). Entretanto, como visto nos fragmentos narrativos, diferentes expressões da violência intrafamiliar ou perpetrada por parceiros íntimos são associadas às tentativas de suicídio entre as entrevistadas. Elas vivenciaram situações de agressão diversas, como psicológica, física e sexual. Na maioria, a violência física estava direcionada a elas, porém algumas sinalizaram tê-la presenciado entre os pais e, ou, responsáveis. Ao relatarem sobre suas tentativas de suicídio, falaram das dores e dificuldades em lidar com as situações de violências que marcam transversalmente as histórias.

Os dados corroboram a literatura nacional quando apontam que os principais meios utilizados foram o uso abusivo de medicação, cortes e tentativa de pular de prédios altos. Vale destacar que todas tiveram pelo menos uma tentativa a partir de ingestão de remédios usados para tratamento psiquiátrico.

A pesquisa realizada não esgotou as possibilidades de compreensão da tentativa de suicídio de mulheres jovens, em especial porque estamos diante de uma problemática que é multifacetada. Porém abre um campo de discussão que poderá auxiliar na criação de medidas preventivas. $\mathrm{O}$ estudo teve como limitação o difícil acesso às mulheres que tentaram suicídio, o que demonstrou que falar sobre a temática ainda é um tabu. Muitas mulheres disseram que era importante falar a respeito do tema, mas não estavam preparadas para isso. Ambos os temas que estão associados neste estudo, violências contra mulheres e 
tentativas de suicídio, podem ser experimentados como tópicos sensíveis (Hydén, 2013). Reiteramos que esta não foi uma associação prévia ao estudo. O foco da questão abordada na narração central foi a experiência da tentativa de suicídio. No exercício analítico, foi identificado o relevo dado às situações de violência pelas próprias mulheres. Nem sempre essa relação entre violência e suicídio é autoevidente, sendo mais frequente a medicalização de ambas as experiências. 


\section{REFERÊNCIAS}

Bertolote, J. M. (2012). O suicídio e sua prevenção. São Paulo: Unesp.

Coelho, A. R. (1997). Suicídio: um estudo introdutório. Psicologia \& Sociedade, 9(1-2), 47-64.

Correia, C. M., Gomes, N. P., Couto, T. M., Rodrigues, A. D., Erdmann, A. L., \& Diniz, N. M. F. (2014, janeiro-março). Representações sobre o suicídio para mulheres com história de violência doméstica e tentativa do mesmo. Contexto Enfermagem, 23(1), 118-25.

Correia, C. M., Gomes, N. P., Diniz, N. M. F., Andrade, I. C. S., Romano, C. M. C., \& Rodrigues, G. R. S. (2019, November-December). Child and adolescent violence: oral story of women who attempted suicide. Revista Brasileira de Enfermagem, 72(6), 1450-1456. Recuperado a partir de https:// doi.org/10.1590/0034-7167-2017-0814

Durkheim, E. (2000). O suicídio: um estudo de Sociologia. São Paulo: Martins Fontes.

Faúndez, X., Cancino, M. C., \& Besoain, C. (2017, enero). El análisis de datos en enfoques biográficos-narrativos: desde los métodos hacia una intencionalidade analítica. Forum Qualitative Social Research, Sozialforschung, 18(1), art. 16.

Flick, U. (2009). Introdução à pesquisa qualitativa. (3a ed.). Porto Alegre: Artmed.

Fukumitsu, K. O., Provedel, A., Kovács, M. J., \& Loureiro, A. C. T. (2015). Suicídio: uma análise da produção científica brasileira de 2004 a 2013. Revista Brasileira de Psicologia, 2(1), 5-14.

Fukumitsu, K. O., \& Scavacini, K. (2013, julho-dezembro). Suicídio e manejo psicoterapêutico em situaçôes de crise: uma abordagem gestáltica. Revista da Abordagem Gestáltica - Phenomenological Studies, 19(2), 198-204.

Guimaraes, R. C. S., Soares, M. C. S., Santos, R. C., Moura, J. P., Freire, T. V. V., \& Dias, M. D. (2018). Impacto na autoestima de mulheres em situação de violência doméstica atendidas em Campina Grande, Brasil. Revista Cuidarte, 9(1), 1988-1997._Recuperado a partir de https://revistas.udes.edu.co/cuidarte/ article/view/438 
Hydén, M. (2013). Narrating sensitive topics. In M. Andrews, C. Squire, \& M. Tamboukou, M. (Eds.), Doing narrative research. (2nd ed.). (pp. 223-239). London: Sage.

Jovchelovitch, S., \& Bauer, M. W. (2007). Entrevista narrativa. In M. W. Bauer, \& G. Gaskell. Pesquisa qualitativa com texto, imagem e som: um manual prático. (6a ed.). (pp. 90-113). Petrópolis: Vozes.

Lawrenz, P., Macedo, D. M., Hohendorff, J. V., Freitas, C. P. P., Foschiera, L. N., \& Habigzang, L. F. (2018). Violência contra mulher: notificações dos profissionais da Saúde no Rio Grande do Sul. Psicologia: Teoria e Pesquisa, 34. Recuperado a partir de https://dx.doi.org/10.1590/0102.3772e34428

Lei no 13.819, de 26 de abril de 2019. (2019, 26 abril). Institui a Política Nacional de Prevenção da Automutilação e do Suicídio, a ser implementada pela União, em cooperação com os Estados, o Distrito Federal e os Municípios; e altera a Lei no 9.656, de 3 de junho de 1998. Diário Oficial da União, Brasília.

Macedo, J. L. S., Rosa, S. C., \& Silva, M. G. (2011). Queimaduras autoinfligidas: tentativa de suicídio. Revista Colégio Brasileiro de Cirurgióes, 38(6), 387-391.

Maciel, V. (2017, 21 setembro). Taxa de suicídio é maior em idosos com mais de 70 anos. Brasília: Ministério da Saúde, Agência Saúde. Recuperado a partir de https:/www.gov.br/saude/pt-br/assuntos/noticias/taxa-de-suicidio-e-maiorem-idosos-com-mais-de-70-anos

Maciel, V. (2018, 20 setembro). Novos dados reforçam a importância da prevenção do suicídio. Brasília: Ministério da Saúde, Agência Saúde. Recuperado a partir de https://www.gov.br/saude/pt-br/assuntos/noticias/novos-dados-reforcama-importancia-da-prevencao-do-suicidio

Marín-León, L., \& Barros, M. B. A. (2003). Mortes por suicídio: diferenças de gênero e nível socioeconômico. Revista Saúde Pública, 37(3), 357-363.

Meneghel, S. N., Hesler, L. Z., Ceccon, R. F., Trindade, A. G., \& Pereira, S. (2013). Suicídio de mulheres: uma situação limite? Athenea Digital, 13(2), 207-217.

Meneghel, S. N., Moura, R., Hesler, L. Z., \& Gutierrez, D. M. D. (2015). Tentativa de suicídio em mulheres idosas: uma perspectiva de gênero. Ciência \& Saúde, 20(6), 1721-1730.

Minayo, M. C. S. (2007). Trabalho de campo: contexto de observação, interação 
e descoberta. In M. C. S. Minayo, S. F. Deslandes, \& R. Gomes (Orgs.), Pesquisa social: teoria, método e criatividade. (26a ed.). (pp. 61-77). Petrópolis: Vozes.

Minayo, M. C. S., \& Cavalcante, F. G. (2013, dezembro). Estudo compreensivo sobre suicídio de mulheres idosas de sete cidades brasileiras. Cadernos de Saúde Pública, 29(12), 2405-2415.

Ministério da Saúde. (2006). Prevenção do suicídio: manual dirigido a profissionais da equipe de saúde mental. Brasília: Ministério da Saúde.

Ministério da Saúde. (2018, junho). Secretaria de Vigilância em Saúde. Análise epidemiológica da violência sexual contra crianças e adolescentes no Brasil, 2011 a 2017. Boletim Epidemiológico, 49. Recuperado a partir de https:// antigo.saude.gov.br/images/pdf/2018/junho/25/2018-024.pdf

Pinto, V. C. P., Alves, J. F. C., \& Maia, A. C. (2015, outubro-dezembro). Adversidade na infância prediz sintomas depressivos e tentativas de suicídio em mulheres adultas portuguesas. Estudos de Psicologia, 32(4), 617-625.

Santos, A. S., Lovisi, G., Legay, L., \& Abelha, L. (2009, setembro). Prevalência de transtornos mentais nas tentativas de suicídio em um hospital de emergência no Rio de Janeiro, Brasil. Cadernos de Saúde Pública, 25(9), 2064-2074.

Souza, T. M. C., Pascoaleto, T. E., \& Mendonça, N. D. (2018, setembrodezembro). Violência contra mulher no namoro: percepções de jovens universitários. Revista Psicologia e Saúde, 10(3), 31-43._Recuperado a partir de http://dx.doi.org/10.20435/pssa.v10i3.695

Tavares, D., Quevedo, L., Jansen, K., Souza, L., Pinheiro, R., \& Silva, R. (2012, October). Prevalence of suicide risk and comorbidities in postpartum women in Pelotas. Revista Brasileira de Psiquiatria, 34(3), 270-276. 